\title{
Climate information requirements for community-level risk management and adaptation
}

\author{
G. Srinivasan ${ }^{1, *}$, Kareff May Rafisura ${ }^{2}$, A. R. Subbiah ${ }^{1}$ \\ ${ }^{1}$ Regional Integrated Multi-hazard Early-warning System (RIMES) for Africa and Asia, Asian Institute of Technology (AIT), \\ PO Box 4, Klong Luang, Pathumthani 12120, Thailand \\ ${ }^{2}$ United Nations Development Programme, United Nations House, PO Box 107, Pulchowk, Lalitpur, Nepal
}

\begin{abstract}
Climate information can be of value when used in decisions involving risks posed by adverse weather or climate. Socio-economic factors such as increasing population in regions susceptible to climate extremes significantly increase the vulnerability of communities to climate. Climate information is an important pre-requisite for informed decision-making in risk management and adaptation that would help prevent climate extremes from becoming disasters and threats to livelihoods. Reliable weather, climate and water information generated by national meteorological and hydrological services (NMHSs) is the crucial first step in issuing early warnings of potential climate extremes. In order for climate information to inform risk management and adaptation effectively, it is helpful to have it embedded within an institutional system that starts with monitoring of weather and climate events and ends with a community level response. This institutional system contains a number of components, of which perhaps the most important is the customization of information according to user requirements and its delivery to the community level. Policies and projects aimed at creating and facilitating systemic linkages between climate information producers and users can contribute significantly towards the 'community centeredness' of climate services. Experiences from implementing such community level activities in Asia are used to recommend actions required for evolving frameworks for developing community-centered climate services.
\end{abstract}

KEY WORDS: Climate Services · Climate information - Climate risk management · Adaptation · Climate Change

Resale or republication not permitted without written consent of the publisher

\section{INTRODUCTION}

Poor communities dependent on economic activities influenced by climate are exposed to risks brought about by climate variability and change at local scales. Many communities in the tropical Asian region are particularly vulnerable since they are exposed to several hydro-meteorological hazards due to factors such as longer cyclone seasons, 2 cyclone seasons, the considerable influence of El Niño, and the variable and frequently heavy rainfall associated with monsoons. Current climate variability, viewed along with future climate change scenarios, highlights the need for delivering climate information in a timely manner.
Effective use of weather and climate information to manage current climate risks and prepare adaptive actions to face future changes is therefore urgently needed. In fact, the use of information to manage climate risks to livelihoods is not new for many communities in the Asian region. In many cases, indigenous practices show that there is a demand for climate information and a culture of using it. Indigenous institutional arrangements have developed to meet these demands (Box 1).

However, science-based institutions have not been able to fully exploit the opportunity to integrate science-based climate information into community level decision making. In most cases, the information pro- 
Box 1. An indigenous system for meeting climate information requirements

The island of Nusa Tenggara Timur, Indonesia, is drier compared to most regions of Indonesia because of its relative distance from the Inter-tropical Convergence Zone and the rain shadow effect of other islands. However, the problems that most subsistence farmers face are not associated with the low rainfall amount but the very high annual rainfall variability. Climate information, including the timing of the rainfall onset and withdrawal is very critical in deciding when and what to plant. Information regarding rainfall intensity is also important in selecting the right place to cultivate for a particular season (welldrained soils produce better during wet years while clayey valleys produce better during dry years)

A well-respected member of the clan, known as 'tobe' in the local language, is responsible for giving seasonal prediction based on various environmental indicators. The tobe's prediction is the basis for managing the agricultural season in his clan's shared farmlands. Decisions, which to a large extent depend on the predictions made by the tobe, are the choice of cultivars, the size allocated for each cultivar, and the timing of planting.

While the scientific rigor of the tobe's prediction is not verified, this case illustrates that several critical livelihood decisions are climate-information dependent and institutions develop over time to fulfill the demand for information.

(Field work in Nusa Tengara Timur from 6 to 11 March 2009, authors' unpubl. data)

duced by national meteorological and hydrological services (NMHSs) and some research institutes have spatial and temporal limitations. Because seasonal climate information is prepared for a broad geographic area and for time domains that do not match the community's decision making horizons, the information has very limited relevance to community level concerns. Long-term climate projections, usually made for 50, 80 and $100 \mathrm{yr}$ time slices, also have the same limitations. As communities are concerned about more immediate issues and crisis, their demand is for information about climate extremes and risks, rather than the changes in climate that are foreseen to occur many decades into the future.

This study demonstrates that the management of current climate risks and long-term adaptation at the community level require customation of climate information in order to make it relevant to individual communities. Meeting the demand for climate information is possible only when we are able to develop institutional systems that connect information providers with users. Doing this requires a major shift from the technology- or science-centric top-down approach currently followed by a large number of public climate information providers, to a bottom-up approach that puts the user requirements at the core. Climate infor- mation should be a function of the user rather than the technology used to produce it.

The outline of this paper is as follows: (1) explanation of the key concepts used in the paper, (2) requirements of climate information for community based climate risk management and adaptation, (3) discussion of the gaps in current climate information generation and application systems, and finally (4) we offer some insights for evolving a framework for meeting the climate information requirements for community level risk management and adaptation using case studies from Southeast Asia.

\section{EXPLANATION OF KEY CONCEPTS}

In academic discourse, it is customary to differentiate between weather (the condition of the atmosphere at a given time) and climate (the average weather). However, it is important to recognize that Asian communities tend not to distinguish between weather and climate products because in many native languages in Asia there is no clear distinction between terminologies used for weather and climate. Although, we maintain the distinction between weather and climate prediction and the different methodologies for generating them, they are often perceived as a seamless process from the user's perspective. In most cases, we also observe that the institutional systems used for generating and delivering weather and climate information are the same. In practice, users see managing both weather and climate risk as part of the same strategy. Hence in this paper, examples include both weather and climate 'scales'.

We adopt the user perspective in this paper and use the term 'climate information' to describe the following along with their derivatives: (1) past climate data and analysis products - usually climate statistics; (2) Forecasts - nowcasts: within $24 \mathrm{~h}$; short-range: 1 to $3 \mathrm{~d}$; medium-term range: 3 to $15 \mathrm{~d}_{\text {; }}$ extended range or seasonal: $15 \mathrm{~d}$ to $1 \mathrm{mo}$; long-range or seasonal: $>1$ to $6 \mathrm{mo}$; yearly to decadal: 1 to $10 \mathrm{yr}_{\text {; }}(3)$ climate change projections $\longrightarrow 10$ to $100 \mathrm{yr}$ climate prediction based on past climate information.

Climate risk is defined as the possibility of injury, damage to property, or financial loss owing to severe or extreme weather events, unusual seasonal variation such as heat waves or droughts, or long-term changes in climate or climate variability.

Climate risk management is an approach to decision making in climate sensitive activities that aims to maximize the positive and minimize the negative influence of weather or climate.

Adaptation is a concept that originated from ecology, which is defined as 'characteristics that help living 
organism survive under a given set of environmental conditions' (Miller 2005, p. 90). The Intergovernmental Panel on Climate Change (IPCC 2007, p. 869) defines adaptation as the 'adjustment in natural or human systems to a new or changing environment.' Although the concept remains the same in the climate change context, 'adaptive traits' in ecosystems are acquired genetically over much longer time-scales, whereas the 'adaptive capacities' of communities need to be built within shorter time spans defined by adverse climate change scenarios.

It is important to point out that communities have been rendered more vulnerable to current climate risks due to several non-climatic factors, such as settlement patterns, high population density and poverty. Hence adaptation is not only about making adjustments in natural and human systems to deal with a 'moving target', i.e. a changing climate, but is also about addressing long standing development issues that make people vulnerable to the impacts of climate change.

In the light of the growing international attention given to anthropogenic climate change, more attention is given to linking climate change adaptation and disaster risk reduction because of the growing evidence that climate change will likely increase the frequency and intensity of extreme climate events. Climate risk management is being proposed as one approach that bridges disaster risk reduction and adaptation.

\section{INFORMATION REQUIREMENTS FOR MANAGING CURRENT RISKS AND PLANNING FUTURE ADAPTATION STRATEGIES}

Climate risk management and adaptation strategies can minimize the loss of life and damage to assets, infrastructure, and crop production from natural climate variability and extreme climate events. Table 1 summarizes the broad range of weather and climate information and their respective uses for decision making.
Knowledge of the evolving patterns of climate variables on a decadal-to-century time scale enables better planning and utilization of scarce resources. For example, in southwest Asia the bulk of cereal production depends on irrigation water from snow melt that feeds the rivers. The amount of snow pack and changes in temperature during December to April determine the availability of water for the ensuing months, and thus the stored soil moisture for subsequent spring, summer and winter crops.

In the winter of 1999, Ghazni province in Iran received only $33 \%$ of its normal snowfall and experienced a 3 to $5^{\circ} \mathrm{C}$ increase in daily minimum temperatures in the spring, which accelerated snow melt and enhanced river flow in north, northeastern and eastern provinces in mid-May. This increased river flow was untimely for both the ripening wheat crop and the as yet unplanted second cereal crop. Strategically placed monitoring systems for snow cover and seasonal temperature predictions could have provided climate information with several months lead time for decision makers and farming communities, allowing more effective planning for the subsequent agricultural seasons (ADPC 2002).

Both regional and global assessments of climate change suggest that climate change will involve enhanced variability in heavy rainfall and drought events (Solomon et. al 2007, Allison et al. 2009). Adaptation plans addressing risks from climate extremes over the next 5 to $10 \mathrm{yr}$ - a time frame that is within the planning horizons of national governments - will be important for the wellbeing of communities. The effective use of climate information in adaptation planning can help prevent weather and climate extremes from becoming either disasters or threats to livelihoods.

Requirements of climate information for adaptation at community level can be appreciated better if viewed in light of the magnitude of changes in modelgenerated scenarios alongside date ranges listed in Table 2. The 3 date ranges generally used (Solomon et al. 2007, Meehl et al. 2007) for climate change projections, covering the next century, represent an early-

Table 1 Availability of climate information for community level users

\begin{tabular}{|c|c|c|c|c|}
\hline Climate information & Time scale & Space scale & Products & User sector \\
\hline Climate change & $\begin{array}{l}\text { Decades to } \\
\text { centuries }\end{array}$ & $\begin{array}{l}\text { Global } \\
\text { Continental }\end{array}$ & Scenarios of change & $\begin{array}{l}\text { Long-term planning in all } \\
\text { climate-sensitive sectors }\end{array}$ \\
\hline Climate variability & $\begin{array}{l}\text { Years } \\
\text { Seasons } \\
\text { Months }\end{array}$ & $\begin{array}{l}\text { Continental } \\
\text { Regional } \\
\text { National }\end{array}$ & $\begin{array}{l}\text { Guidance } \\
\text { Outlooks } \\
\text { Predictions }\end{array}$ & $\begin{array}{l}\text { Agriculture } \\
\text { Water resource } \\
\text { Planning } \\
\text { Energy } \\
\text { Health }\end{array}$ \\
\hline Weather & $\begin{array}{l}1 \text { week } \\
\text { Days } \\
\text { Hours } \\
\text { Minutes }\end{array}$ & Location specific & $\begin{array}{l}\text { Threat assessments } \\
\text { Forecasts } \\
\text { Watches } \\
\text { Warnings and alerts }\end{array}$ & $\begin{array}{l}\text { Protection of life and property losses } \\
\text { Water management } \\
\text { Transport } \\
\text { Fire weather }\end{array}$ \\
\hline
\end{tabular}


Table 2. Global mean warming $\left({ }^{\circ} \mathrm{C}\right)$ projected for 3 date ranges relative to 1980-1999 from the IPCC multi-model ensemble mean (Solomon et. al 2007, Meehl et al. 2007). Warming: Special Report on Emissions Scenarios (A2, A1B and B1)

\begin{tabular}{|ll|}
\hline Warming & $\begin{array}{l}\text { Potential applications after suitable } \\
\text { downscaling }\end{array}$ \\
\hline $\mathbf{2 0 1 1 - 2 0 3 0}$ & \\
0.66 & $\begin{array}{l}\text { Most suitable for use in development projects } \\
\text { (with 3 to 5 yr duration) }\end{array}$ \\
& $\begin{array}{l}\text { Also useful for long-term planning of provin- } \\
\text { cial government authorities for their 5 to 10 yr } \\
\text { development plans }\end{array}$ \\
$\mathbf{2 0 4 6 - 2 0 6 5}$ & As background information for macro-level \\
1.56 & development, policy, and fiscal planning \\
$\mathbf{2 0 8 0 - 2 0 9 9}$ & Mega infrastructure projects \\
2.52 & \\
\hline
\end{tabular}

century period (2011-2030), a mid-century period (2046-2065), and the late-century period (2080-2099). Temperature is not generally the most critical climate variable in tropical Asia; however it used here for its relative reliability over rainfall projections.

Although Table 2 pertains to global means, it illustrates the relevance of climate information from projections for the early-century period. Communities can adapt to long-term climatic changes through the same institutional systems used for managing current climate risks. The other time horizons are typically more appropriate at macro governance levels that have longer time horizons, such as in national development and fiscal planning. As a suitable strategy for adaptation and development planning, Wilby et al. (2009) recommend assessments of vulnerability to current climate extremes and variability, and evaluation of sector specific incremental risk over the next few decades.

At present, many adaptation projects at the community level try to use climate variability information to optimize opportunities and manage risks in various sectors. This produces collateral benefits for adaptation as climate considerations get mainstreamed into the decision making process at the community level. When communities are able to manage climate variability, their decision environments are more receptive to using climate information for long-term adaptation planning as well.

\section{GAPS IN THE CURRENT EFFORTS TO DEVELOP USER-CENTRIC INFORMATION}

Although a lot of experts and policymakers are sympathetic to the idea of connecting providers and users in an end-to-end system of climate information generation and application, field progress is rather slow. While the idea seems straightforward, the implementation is far from being simple and automatic. This section will discuss the gaps in the current efforts, drawing heavily from both the authors' observations and first hand experiences in Asia. In collaboration with international research centers, donors, national hydro-meteorological services and partners at national and local levels, a number of efforts have been undertaken to assist countries in establishing end-to-end climate information applications system in order to reduce climate risks.

Different countries in Asia are in different stages of establishing climate information applications systems, but in general, the common weaknesses are as follows:

(1) Mismatch between the temporal and spatial scale of the forecasts and the scales required for decisionmaking. As a result, climate information is not tailored to user requirements. For instance, in most countries, only information on seasonal rainfall totals is available but for most farming systems, the distribution of rainfall within a season, as well as probabilities of a dry or wet spell within a season, are more critical.

(2) Absence of mechanisms that involve the users for identifying their climate information requirements. As a result, meteorologists forecast what they know rather than produce information that meets the requirements of the users.

(3) Lack of experience in communicating probabilistic scientific information for sectoral use, primarily because forecasters are not trained to communicate with user agencies and communities. In the scientific sense, forecasts are probabilistic and hence, they never go 'wrong'. However users often interpret forecasts in a deterministic manner (Box 2).

(4) Weak forecast producer-user communication channels.

(5) Users have no mechanism for processing information once it is received.

In many situations, a combination of these factors result in inaction and mismanagement, leading to losses of property and life. The sudden floods that submerged most of the city of Surat, Gujarat, India, from 7 to 8 August 2006 is an appropriate example (SANDRP 2007). The flooding took place due to the release of large amount of water from the Ukai dam within a short period of time. Despite the heavy rainfall in the upper catchments of the basin and the very heavy rainfall warning issued by the India Meteorological Department (IMD) on 3 August for the basins that feed the dam from the Narmada, Tapi and Damanganga rivers (Gujarat state, western India), the dam managers did not release water until 4 d later. This can be attributed partly to the lack of awareness of the consequences of delayed action and partly to the lack of confidence in the rainfall and runoff information provided by the NHMS. 
Box 2. Probabilistic forecasts

Although forecasts are probabilistic, they are often interpreted by users in a deterministic manner. Hence trouble ensues when the event with the highest probability does not materialize. In 1997, for example, scientists and US aid agencies warned farmers in Southern Africa of the high likelihood of drought as ENSO developed, and advised them to plant early. But unlike the 1991-1992 ENSO, no drought materialized. At the end of the agricultural season much of Southern Africa experienced a grain supply shortage, not because of ENSO but in part because of the seasonal forecast, which had caused a lot of farmers to alter their planting routine (Sarewitz et al. 2000).

Although the example is based on a weather event, the case clearly illustrates the need for building an understanding on using climate information effectively to manage risks. If systems have to cope with increasing number of extremes, they need to act on different kinds of climate information at various time scales. In this particular case, the first level of preparation could be based on a seasonal outlook for a wetter than normal rainy season. Alerts at longer lead times and more specific measures at shorter time scales could be initiated subsequently as the information become available. User agencies and communities must be able to respond to a series of risk thresholds which trigger a sequence of risk reduction measures calibrated for different threshold levels. There is a need for evolving a system that will translate information into recommended actions (e.g. alert, warnings, evacuation order) and finally, deliver the information to the communities that are at risk.

\section{EVOLVING A FRAMEWORK FOR DEVELOPING COMMUNITY-CENTRIC CLIMATE SERVICES}

The persistence of these weaknesses underlines the need for policies and programs on the part of national governments and allied agencies that are responsible for climate services. In high revenue business sectors, particularly in developed countries, private services have stepped in quite successfully. But vulnerable communities in developing and least developed countries do not have access to such services, except for some cases where NGOs and development agencies have taken up specific projects. Before offering some insights based on our experiences in various Asian countries, it is worth discussing some of the often overlooked aspects about climate information applications.

First, we need to bear in mind that provision of climate information in itself cannot ensure the high quality of decisions that are required for building long-term resilience in communities to climate risks. The US
National Research Council Panel study (NRC 2009, p. 21) observes that 'decisions depend not only on the quality and availability of information, but also on the ways people-working individually or in groups process information and evaluate options'. Lugon (2010, p 12) observes that 'many policies fail because experts believe that better science will automatically lead to better decisions without fully understanding the specific situation and the institutional context within which the climate information is to be used.'

Second, it is important to understand that climate information needs to be packaged with other information and services in order to be usable. Climate information is only one component of an entire package of rural agricultural extension services that should include input support and extension support services. The participation of the private sector in providing seeds and a market is indispensable. Farmers are more willing to respond to forecasts when there is a market certainty. The experience of Indramayu (a key rice producing district in West Java, Indonesia) during the 2006 El Niño offers an interesting case study to prove this point (ADPC 2009). A large percentage of farmers planted soybeans instead of paddy rice when the NHMS predicted a delayed monsoon onset. One of the key reasons was the market guarantee provided by an agreement between the district government and a buyer company.

Providing climate information at community level is constrained by the limitations of the present global modeling systems to produce location-specific forecasts. Although high-resolution weather forecast models have made it possible to give reliable local weather predictions at shorter time scales ( 1 to $5 \mathrm{~d}$ ), site-specific information for climate predictions and change scenarios cannot be made with confidence. Regionalization or downscaling of climate predictions and scenarios from coarse-resolution Global Climate Models (GCMs) do offer some level of guidance, but with associated uncertainties. The potential utility of such climate information of limited skill can be only realized by understanding the critical points in the decision-making process specific to a given situation in each community within a given context, and by developing reliable climate information tailored to these needs. The NHMS, in partnership with relevant agencies, require a thorough understanding of a community's exposure to risk from climate change and how the community might most efficiently and effectively adapt to future changes in climate. This requires understanding livelihood patterns vis-à-vis the climatology of the region. Using historical data on how the community responded or was impacted by climate variations and extremes in the past is also important. Climate sensitive decisions associated with livelihood actions like planting, harvesting, 
seasonal migration to the city or lowland or highland areas, and moving livestock to other locations, needs to be mapped out in order to determine the type of information required and when it is needed.

The methodology for establishing climate information generation and applications systems could vary from one country to another depending on institutional and policy contexts. A 6 step methodology is followed by the Asian Disaster Preparedness Center (ADPC) in implementing the Climate Forecast Applications (CFA) for Disaster Mitigation Program, which was supported by the US Agency for International Development's Office of Foreign Disaster Assistance (USAID /OFDA) from 2003 to 2009 (ADPC 2009). The program methodology consists of:

(1) Assessment of user information needs and existing capacities of national hydro-meteorological institutions to meet these needs.

(2) Assessment of relevance of latest scientific information to meet these needs.

(3) Developing partnerships and enhancing capacities of national institutions to generate climate information.

(4) Institutional development to communicate information to end-users (pilot demonstrations, scaling up, and institutionalization).

(5) Applying information to enable proactive decision making.

(6) Monitoring and evaluation of applicability of information.

\subsection{Connecting information providers and users}

An effective climate service goes beyond the production of information. It has to be embedded into an end-to-end system that serves the members of target community with information that would enable them to initiate actions to reduce or avoid risks.

Intermediate organizations should be involved with various levels of customization of the climate information to enable enhanced utility for the concerned communities. An illustrative case in point is Bangladesh, where downstream floods caused by heavy rainfall episodes in the Ganges-Bhramaputra basin (combined drainage area $\sim 1662000 \mathrm{~km}^{2}$ ) cause human suffering almost every year. Webster \& Hoyos (2004) showed the possibility of using physically based statistical schemes to predict rainfall with lead times of more than $10 \mathrm{~d}$ in the monsoon region. Based on this and subsequent research, the CFA in Bangladesh (CFAB ${ }^{1}$ ) project, sup-

\footnotetext{
${ }^{1}$ Agencies collaborating with CFAB were the Program in Atmospheric and Oceanic Sciences at the University of Colorado, Boulder; Georgia Institute of Technology; European Centre for Medium-Range Weather Forecasts (ECMWF); Bangladesh Meteorological Department (BMD); Bangladesh Flood Forecast and Warning Centre (FFWC); and ADPC in Thailand.
}

ported by USAID/OFDA, was launched during the monsoon of 2003 and 2004. Long-lead forecasts for rainfall in the river basin were given using the UKbased European Centre for Medium-Range Weather Forecasts (ECMWF), Tropical Rainfall Measuring Mission (TRMM) and other datasets (Hopson 2005).

The CFAB project demonstrates how scientific information can be leveraged and institutions brought together to minimize climate risks at community levels. Fig. 1 provides a schematic of institutional linkages built during the CFAB project. Coordinated efforts by ADPC, BMD and the Institute for Water Modeling (IWM) resulted in the development of 1 to $10 \mathrm{~d}$ discharge forecasts at major stations of 2 rivers (Hardinge Bridge on the Ganges, and Bahadurabad on the Bhramaputra). The FFWC was responsible for producing local level forecasts in other locations along these rivers. The Center for Environmental and Geographic Information Services (CEGIS) disseminated flood forecasts to communities during the monsoon season, working in close coordination with the Disaster Management Bureau (DMB) and the Department of Agricultural Extension (DAE).

With additional lead times and tailored warnings, community level flood risks were better managed. Communities were able to mobilize in advance, e.g. move livestock to higher ground and secure fishing nets, in order to protect their livelihood assets. The

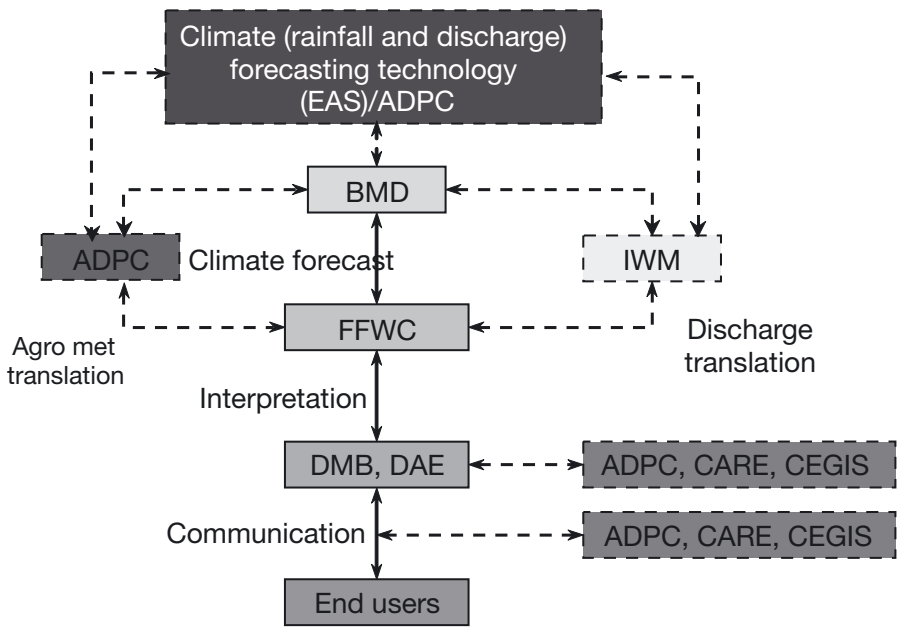

Fig. 1. Linkages established between different partnering institutions for long lead (1 to $10 \mathrm{~d}$ ) forecast of rainfall. Solid lines denote flow of forecasts and products while broken lines indicate coordination between the institutions involved, namely Asian Disaster Preparedness Centre (ADPC); GeorgiaTech - Earth Atmospheric Sciences (EAS); University of Colorado, which colloborated with EAS; Bangladesh Meteorological Department (BMD); Flood Forecasting and Warning Centre (FFWC) of the Bangladesh Water Development Board (BWDB), Disaster Management Bureau (DMB); Department of Agricultural Extension (DAE); Center for Environmental and Geographic Information Services (CEGIS); and CARE Bangladesh 
project ran a second phase from 2006 to 2009 with support from USAID Bangladesh through CAREBangladesh. The objective was to transfer technology from the US to Bangladesh and to build the capacity of national and local institutions for a sustainable end-toend generation and application of flood forecast products in high-risk locations.

\subsection{Strengthening producer-user interface through climate forums}

Climate forums were initiated by ADPC in several countries in Asia, including Mongolia, Myanmar, Sri Lanka, and Vietnam, in order to build institutional mechanisms for communicating forecasts to users and for allowing feedback from users to providers. It is a regular 2-way dialogue and multi-stakeholder process of understanding and applying climate information. It is usually initiated and facilitated by the national hydrometeorological agency and includes participation by different stakeholders from the public and private sectors.

Indonesia and the Philippines have extensive experiences with respect to institutionalizing climate forums at national and local levels. In March 2003, the Philippine Atmospheric Geophysical and Astronomical Services Administration (PAGASA) initiated the National Level Climate Forum in the aftermath of 2 severe El Niño events (1997-1998 and 2002-2003) that dramatically demonstrated the need to establish a platform for discussing climate forecasts. The holding of a local level climate forum was also initiated at the province level under the USAID/OFDA supported CFA Program.

In general, the objectives of the climate forum are (1) to ensure that forecast products, including their uncertainties and limitations, are understood by and communicated to users; (2) to encourage CFA for mitigating risks in various climate-sensitive sectors; and (3) to provide a platform for interagency coordination of policies and programs for dealing with potential impacts of climate related hazards on a season-to-season basis.

The mechanics and specific objectives of climate forums may vary from one country to another in recognition of the diverse institutional characteristics and mandates. In order to ensure regularity, the climate forum is anchored around a recurring phenomenon, such as the onset of the monsoon. Meetings are convened at least twice a year, just before the onset of the monsoon and after the monsoon. The nature of risks and opportunities characterizing each season vary to a great extent hence it is important that the forecast providers and users meet more frequently to make sure that the nature and timing of risks are well understood.

In order to make a climate forum successful, several elements have to be present. First, the users must be willing to participate and constantly engage the hydrometeorological service. Second, the national hydrometeorological agency should have a good understanding of the user context. It should have an understanding of:

(1) Who are the users and what are their key activities, e.g. water resources management, agriculture, disaster management or public health?

(2) What kind of climate information do they need to carry out their functions more effectively, and when is this information needed?

(3) Do they have the capacity to receive, interpret, and translate climate forecasts into sectoral impacts? If not, what capacity building activities are needed?

Having a communication plan between forecast providers and users is essential. There should be regularity in releasing forecast information. Users should also give regular feedback to the national hydrometeorological agencies in the form of post-season reports or other channels. Finally, users, specifically user agencies, must have a mechanism for receiving and utilizing climate information within their respective organizations.

Our experience in Myanmar indicates that sometimes there is no need to come up with entirely new mechanisms for allowing feedback from users to NHMSs because some user agencies have a longstanding practice of preparing post-monsoon season reports. These reports could be enhanced to document events and issues that would serve the purpose of monitoring the results of using climate information, such as what were the expected and actual climates as forecasted by the hydro-meteorological agency? What were the options considered or recommended by the department and end users? What options were adopted as the season progressed? What were the impacts? And what were the lessons learned?

\section{SUMMARY}

In March 2007 the World Meteorological Organization (WMO) organized 'The International Conference on Secure and Sustainable Living: Social and Economic Benefits of Weather, Climate and Water Services' (WMO 2007). The Conference looked at decision-making techniques related to use of climate information and the need for more work for further development. Although the need for orienting climate services to users has been generally agreed upon, the progress in these efforts needs to become operational soon.

For climate services to make a difference to communities, they have to provide customized solutions and not generic products. Attention should also be given to 
developing the institutional delivery mechanisms for such products. The meteorological services have been founded and evolved on the bedrock of observations and science, a focus that needs to be maintained to bring much-needed progress in climate science and technology. However, there is also a need to connect with societies.

It is urgent to develop mechanisms for delivery of climate services at community levels in a bottom-up manner so that the process remains user-driven. Partnerships between NHMS and relevant government agencies should be forged. The approach could start in the form of time-bound demonstration projects that could be gradually scaled up to larger, homogeneous climate-service units for sustained implementation. Within the institutional system for climate information generation and services, there is a need for a mechanism that can identify appropriate research findings and demonstrate their potential use in sectors and communities.

Acknowledgements. The support of donor agencies viz. United States Agency for International Development, United Nations Development Programme, Danish Agency for International Development, Oxfam Hong Kong, Ministry for Foreign Affairs of Finland, American Red Cross, International Federation of Red Cross, International Strategy for Disaster Reduction, and Food and Agriculture Organization of the United Nations, and the collaborative efforts of technical institutions, NMHSs and other governmental and nongovernmental agencies involved in our projects are gratefully acknowledged. The paper has benefited immensely from the critical comments and constructive suggestions made by Dr. R. J. Murnane of the Bermuda Institute for Ocean Sciences (BIOS) and one other anonymous reviewer. We also thank the editor, Dr. T. C. Peterson, NOAA, for encouraging remarks, and going through the manuscript and revisions, as well as making helpful suggestions that have improved the paper.

\section{LITERATURE CITED}

ADPC (Asian Disaster Preparedness Center) (2002) Climate variability and information applications in Southwest Asia. Technical paper, Asian Disaster Preparedness Center, Bangkok

ADPC (2009) Climate forecast applications for disaster mitigation in Southeast Asia: final implementation report. Asian Disaster Preparedness Center, Bangkok

Allison I, Bindoff NL, Bindschadler RA, Cox PM and others (2009) The Copenhagen diagnosis, updating the world on the latest climate science. The University of New South Wales Climate Change Research Centre (CCRC), Sydney
Hopson T (2005) Operational flood-forecasting for Bangladesh. PhD dissertation, Department of Astrophysical, Planetary, and Atmospheric Science, University of Colorado, Denver, $\mathrm{CO}$

IPCC (2007) Climate change 2007: impacts, adaptation and vulnerability. In: Parry ML, Canziani OF, Palutikof JP, van der Linden PJ, Hanson CE (eds) Contribution of Working Group II to the Fourth Assessment Report of the Intergovernmental Panel on Climate Change. Cambridge University Press, Cambridge

Lugon R (2010) Climate information for decision making: lessons learned from effective user-provider communication schemes. The Graduate Institute, Geneva Centre for International Governance, Geneva

Meehl GA, Stocker TF, Collins WD, Friedlingstein P and others (2007) Global climate projections. In: Solomon S, Qin D, Manning M, Chen Z and others (eds) Climate change 2007: the physical science basis. Contribution of Working Group I to the 4th Assessment Report of the Intergovernmental Panel on Climate Change (IPCC). Cambridge University Press, Cambridge

Miller GT (2005) Living in the environment_principles, connections, and solutions. Brooks/Cole-Thomson Learning, Pacific Grove, CA

NRC (US National Research Council) (2009) Informing decisions in a changing climate. Panel on strategies and methods for climate-related decision support, Committee on the Human Dimensions of Global Change. NRC, Division of Behavioral and Social Sciences and Education, The National Academies Press, Washington, DC

SANDRP (South Asia Network on Dams Rivers and People) (2007) People's Committee on Gujarat Floods 2006: a report. SANDRP, Delhi. Available at www.sandrp.in/drp/ Jul_Aug2007.pdf

Sarewitz D, Pielke RA Jr, Byerly RA Jr (eds) (2000) Prediction: science, decision making, and the future of nature. Island Press, Covelo, CA

Solomon S, Qin D, Manning M, Chen Z, Miller HL (eds) (2007) Summary for policymakers. In: Climate change 2007: the physical science basis. Contribution of Working Group I to the 4th Assessment Report of the Intergovernmental Panel on Climate Change (IPCC). Cambridge University Press, Cambridge. www.sandrp.in/drp/July_Aug 2007.pdf

Webster P, Hoyos CD (2004) Prediction of monsoon rainfall and river discharge on 15-30-day time scales. Bull Amer Meteorol Soc 85:1745-1765

Wilby RL, Troni J, Biot Y, Tedd L and others (2009) A review of climate risk information for adaptation and development planning. Int J Climatol 29:1193-1215

WMO (World Meteorological Organization) (2007) Social and economic benefits of weather, climate and water services. Madrid conference statement and action plan. www.wmo. int/pages/themes/wmoprod/documents/madrid07_Action Plan_web_E.pdf

Proofs received from author(s): March 15, 2011 